General Mathematics Vol. 27, No. 1 (2019), 45-56

DOI:10.2478/gm-2019-0005

sciendo

\title{
Forgotten topological index and reduced Zagreb index of four new operations of graphs ${ }^{1}$
}

\author{
A. Bharali, A. Mahanta, J. Buragohain
}

\begin{abstract}
Indulal and Balakrishnan (2016) have put forward the Indu-Bala product and based on this product four new operations are defined by the authors of this manuscript in the paper "Four new operations of graphs based on Indu-Bala product and the Zagreb indices". In this paper we establish explicit formulas of the forgotten topological index and reduced second Zagreb index in connection with these new operations of graphs.
\end{abstract}

2010 Mathematics Subject Classification: 05C76, $05 \mathrm{C} 07$.

Key words and phrases: forgotten topological index, reduced Zagreb index, operations of graphs.

\section{Introduction}

Topological index, also called molecular structure descriptor, of a chemical compound is a numerical value associated with the chemical compounds which are calculated form its respective molecular graph. Over the years a huge number of graph invariants were introduced and among these Zagreb indices are the oldest vertexdegree based topological indices which are defined by Gutman and Trinajstić [11] in connection with $\pi$-orbital energy of molecules. A flood of publications and research papers were reported since its recognition as topological indices. Some of these studies may be found in $[5,7,10,14,22]$.

The first Zagreb index, $M_{1}(G)$ and second Zagreb index, $M_{2}(G)$ of a graph $G$ are defined as

$$
M_{1}(G)=\sum_{u \in V(G)} d_{G}^{2}(u)=\sum_{u v \in E(G)}\left(d_{G}(u)+d_{G}(v)\right), \quad M_{2}(G)=\sum_{u v \in E(G)} d_{G}(u) d_{G}(v) .
$$

\footnotetext{
${ }^{1}$ Received 27 August, 2018.

Accepted for publication (in revised form) 10 April, 2019
} 
Historically, first and second Zagreb indices are known to be the first topological indices. Many modifications and generalizations of these indices are proposed and studied over the years $[12,17,20]$. Some of the studies of the generalization of the first Zagreb index denoted as $M_{1}^{\alpha}$ may be found in $[15,16]$. For a connected graph $G, M_{1}^{\alpha}$ can be defined as

$$
M_{1}^{\alpha}(G)=\sum_{u \in V(G)} d_{G}^{\alpha}(u) .
$$

This index is also studied under the name of zeroth order general Randic index [20]. For $\alpha=3$, i.e., $M_{1}^{3}(G)=\sum_{u \in V(G)} d_{G}^{3}(u)$ is popularly known as forgotten topological index and is usually denoted as $M_{3}(G)$ [8].

In 2014, Furtula et al. proposed another topological index during their study on difference of Zagreb indices [9]. They named this index as Reduced second Zagreb index, which can be defined as

$$
R M_{2}(G)=\sum_{u v \in E(G)}\left(d_{G}(u)-1\right)\left(d_{G}(v)-1\right) .
$$

In this communication we have considered only the simple connected graphs. Let $G$ be a simple graph. We use $V(G)$ and $E(G)$ to denote the set of vertices and edges of $G$ respectively. $d_{G}(u)$ denotes the degree of the vertex $u$ in $G$. All other graph theoretic notations that are used in this paper are taken from [21].

The fact that along with the atom-atom interactions the intermolecular forces also exist between the atoms and bonds of a molecule leads to the four operations of graph a $G$ viz., $S(G), R(G), Q(G)$ and $T(G)[3]$. For a connected graph $G$, these four related graphs are given as:

- $S(G)$ is the graph obtained by replacing each edge of $G$ by a path of length 2 .

- $R(G)$ is obtained from $G$ by adding a path of length 2 parallel to each of the edges of $G$.

- $Q(G)$ is obtained from $G$ by replacing each edge by a path of length 2 , then joining with edges those pairs of new vertices on adjacent edges of $G$.

- $T(G)$ has as its vertices the edges and vertices of $G$. Adjacency in $T(G)$ is defined as adjacency or incidence for the corresponding elements of $G$.

Different operations of graphs based on these four related graphs were defined and studied in connection with Wiener index [6], Zagreb indices [5, 18, 19] and forgotten index $[1,4]$.

In this paper, we establish formulae for the number of vertices and edges for graphs obtained by the four new operations of graphs. We also propose explicit expressions for the forgotten topological index, Reduced second Zagreb index of these new graph operations. The rest of the paper is organised as follows. In section 2 the new operations of graphs along with some results are discussed. In section 3 and 4 the expressions for forgotten topological index and reduced second Zagreb index are presented and in section 5 conclusions are made. 


\section{The new $F$-sums of graphs}

An example of the four new operations of graphs based on the Indu-Bala product is given in Figure 1. The new $F$-sum of $G_{1}$ and $G_{2}$, denoted by $G_{1} \nabla_{F} G_{2}$, is defined to be the graph with $V\left(G_{1} \nabla_{F} G_{2}\right)=V\left(G_{1}\right) \cup E\left(G_{1}\right) \cup V\left(G_{2}\right)$ and $E\left(G_{1} \nabla_{F} G_{2}\right)=$ $E\left(F\left(G_{1}\right) \nabla G_{2}\right) \backslash E^{*}$, where $\nabla$ is the Indu-Bala product of graphs [13] and $E^{*}=$ $\left\{u v \mid u \in V\left(F\left(G_{1}\right)\right) \backslash V\left(G_{1}\right), v \in V\left(G_{2}\right)\right\}$.

Lemma 1. Let $G_{1}, G_{2}$ be two graphs with $\left|V\left(G_{i}\right)\right|=n_{i}$ and $\left|E\left(G_{i}\right)\right|=m_{i}$, where $i=1,2$. Then,

(a)

$$
d_{G_{1} \nabla_{S} G_{2}}(u)=\left\{\begin{array}{l}
d_{G_{1}}(u)+n_{2} \quad \text { if } \quad u \in V\left(G_{1}\right) \\
2 \text { if } u \in V\left(S\left(G_{1}\right)\right) \backslash V\left(G_{1}\right) \\
d_{G_{2}}(u)+n_{1}+1 \quad \text { if } u \in V\left(G_{2}\right) .
\end{array}\right.
$$

(b)

$$
d_{G_{1} \nabla_{R} G_{2}}(u)=\left\{\begin{array}{l}
2 d_{G_{1}}(u)+n_{2} \text { if } u \in V\left(G_{1}\right) \\
2 \text { if } u \in V\left(R\left(G_{1}\right)\right) \backslash V\left(G_{1}\right) \\
d_{G_{2}}(u)+n_{1}+1 \quad \text { if } u \in V\left(G_{2}\right) .
\end{array}\right.
$$

(c)

$$
d_{G_{1} \nabla_{Q} G_{2}}(u)=\left\{\begin{array}{l}
d_{G_{1}}(u)+n_{2} \quad \text { if } \quad u \in V\left(G_{1}\right) \\
d_{G_{1}}(w)+d_{G_{1}}\left(w^{\prime}\right) \quad \text { if } u \in V\left(Q\left(G_{1}\right)\right) \backslash V\left(G_{1}\right) \\
d_{G_{2}}(u)+n_{1}+1 \quad \text { if } \quad u \in V\left(G_{2}\right),
\end{array}\right.
$$

where in the second case $u$ is inserted into the edge $w w^{\prime} \in E\left(G_{1}\right)$.

(d)

$$
d_{G_{1} \nabla_{T} G_{2}}(u)=\left\{\begin{array}{l}
2 d_{G_{1}}(u)+n_{2} \quad \text { if } \quad u \in V\left(G_{1}\right) \\
d_{G_{1}}(w)+d_{G_{1}}\left(w^{\prime}\right) \quad \text { if } \quad u \in V\left(T\left(G_{1}\right)\right) \backslash V\left(G_{1}\right) \\
d_{G_{2}}(u)+n_{1}+1 \quad \text { if } \quad u \in V\left(G_{2}\right),
\end{array}\right.
$$

where in the second case $u$ is inserted into the edge $w w^{\prime} \in E\left(G_{1}\right)$.

Lemma 2. Let $G_{1}$ and $G_{2}$ be two graphs with $\left|V\left(G_{i}\right)\right|=n_{i}$ and $\left|E\left(G_{i}\right)\right|=m_{i}$, where $i=1,2$. Then

$\left|V\left(G_{1} \nabla_{S} G_{2}\right)\right|=\left|V\left(G_{1} \nabla_{R} G_{2}\right)\right|=\left|V\left(G_{1} \nabla_{Q} G_{2}\right)\right|=\left|V\left(G_{1} \nabla_{T} G_{2}\right)\right|=2\left[n_{1}+m_{1}+n_{2}\right]$.

Lemma 3. Let $G_{1}$ and $G_{2}$ be two graphs with $\left|V\left(G_{i}\right)\right|=n_{i}$ and $\left|E\left(G_{i}\right)\right|=m_{i}$, where $i=1,2$. Then

$$
\left|E\left(G_{1} \nabla_{S} G_{2}\right)\right|=2\left[n_{1} n_{2}+2 m_{1}+m_{2}\right]+n_{2} .
$$




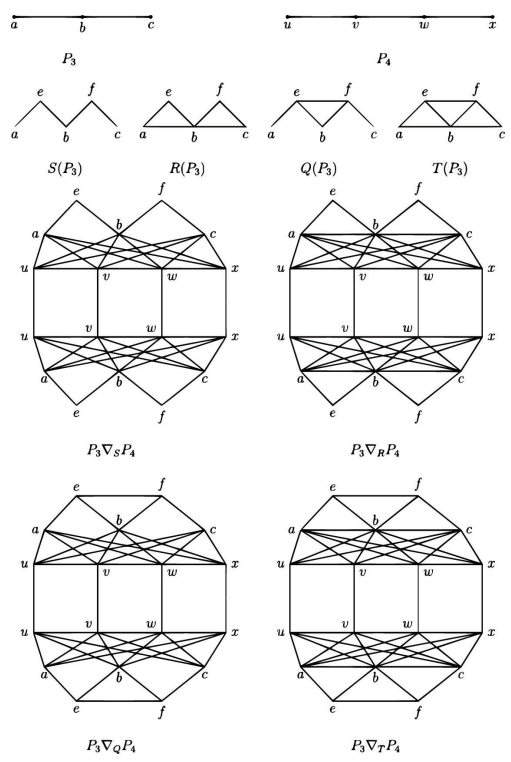

Figure 1: An example of the four new operations of graphs based on Indu-Bala product

Lemma 4. Let $G_{1}$ and $G_{2}$ be two graphs with $\left|V\left(G_{i}\right)\right|=n_{i}$ and $\left|E\left(G_{i}\right)\right|=m_{i}$, where $i=1,2$. Then

$$
\left|E\left(G_{1} \nabla_{R} G_{2}\right)\right|=2\left[n_{1} n_{2}+3 m_{1}+m_{2}\right]+n_{2} .
$$

Lemma 5. Let $G_{1}$ and $G_{2}$ be two graphs with $\left|V\left(G_{i}\right)\right|=n_{i}$ and $\left|E\left(G_{i}\right)\right|=m_{i}$, where $i=1,2$. Then

$$
\left|E\left(G_{1} \nabla_{Q} G_{2}\right)\right|=2\left[n_{1} n_{2}+2 m_{1}+m_{2}+\sum_{v \in V\left(G_{1}\right)}\left(\begin{array}{c}
d_{G_{1}}(v) \\
2
\end{array}\right)\right]+n_{2} .
$$

Lemma 6. Let $G_{1}$ and $G_{2}$ be two graphs with $\left|V\left(G_{i}\right)\right|=n_{i}$ and $\left|E\left(G_{i}\right)\right|=m_{i}$, where $i=1,2$. Then

$$
\left|E\left(G_{1} \nabla_{T} G_{2}\right)\right|=2\left[n_{1} n_{2}+3 m_{1}+m_{2}+\sum_{v \in V\left(G_{1}\right)}\left(\begin{array}{c}
d_{G_{1}}(v) \\
2
\end{array}\right)\right]+n_{2} .
$$

The first Zagreb index and the second Zagreb index of the new $F$-sums of graphs are given below.

Theorem 1. [2] Let $G_{1}$ and $G_{2}$ be two graphs with $\left|V\left(G_{i}\right)\right|=n_{i}$ and $\left|E\left(G_{i}\right)\right|=m_{i}$ where $i=1,2$. Then

$$
\begin{aligned}
M_{1}\left(G_{1} \nabla_{S} G_{2}\right)= & 2\left[M_{1}\left(G_{1}\right)+M_{1}\left(G_{2}\right)+n_{1} n_{2}\left(n_{1}+n_{2}+2\right)\right. \\
& \left.+4\left(m_{1}+m_{2}\right)+4 n_{1} m_{2}+n_{2}\right] .
\end{aligned}
$$


Theorem 2. [2] Let $G_{1}$ and $G_{2}$ be two graphs with $\left|V\left(G_{i}\right)\right|=n_{i}$ and $\left|E\left(G_{i}\right)\right|=m_{i}$, where $i=1,2$. Then

$$
\begin{aligned}
M_{2}\left(G_{1} \nabla_{S} G_{2}\right)= & M_{1}\left(G_{2}\right)+\left(n_{1}+1\right)\left\{n_{2}\left(n_{1}+1\right)+4 m_{2}\right\}+2\left[2 M_{1}\left(G_{1}\right)+\left(n_{1}+1\right) M_{1}\left(G_{2}\right)\right. \\
& +M_{2}\left(G_{2}\right)+m_{2}\left(n_{1}+1\right)^{2}+n_{2}\left(n_{1}+1\right)\left(2 m_{1}+n_{1} n_{2}\right) \\
& \left.+2 m_{2}\left(2 m_{1}+n_{1} n_{2}\right)+4 m_{1} n_{2}\right] .
\end{aligned}
$$

Theorem 3. [2] Let $G_{1}$ and $G_{2}$ be two graphs with $\left|V\left(G_{i}\right)\right|=n_{i}$ and $\left|E\left(G_{i}\right)\right|=m_{i}$, where $i=1,2$. Then

$$
\begin{aligned}
M_{1}\left(G_{1} \nabla_{R} G_{2}\right)= & 2\left[4 M_{1}\left(G_{1}\right)+M_{1}\left(G_{2}\right)+n_{1} n_{2}\left(n_{1}+n_{2}+2\right)\right. \\
& \left.+4 m_{2}\left(n_{1}+1\right)+n_{2}\left(8 m_{1}+1\right)+4 m_{1}\right] .
\end{aligned}
$$

Theorem 4. [2] Let $G_{1}$ and $G_{2}$ be two graphs with $\left|V\left(G_{i}\right)\right|=n_{i}$ and $\left|E\left(G_{i}\right)\right|=m_{i}$, where $i=1,2$. Then

$$
\begin{aligned}
M_{2}\left(G_{1} \nabla_{R} G_{2}\right)= & M_{1}\left(G_{2}\right)+4 m_{2}\left(n_{1}+1\right)+n_{2}\left(n_{1}+1\right)^{2}+2\left[2\left(n_{2}+2\right) M_{1}\left(G_{1}\right)\right. \\
& +\left(n_{1}+1\right) M_{1}\left(G_{2}\right)+4 M_{2}\left(G_{1}\right)+M_{2}\left(G_{2}\right)+m_{2}\left(n_{1}+1\right)^{2} \\
& \left.+n_{2}\left(n_{1}+1\right)\left(4 m_{1}+n_{1} n_{2}\right)+2 m_{2}\left(4 m_{1}+n_{1} n_{2}\right)+4 m_{1} n_{2}+m_{1} n_{2}^{2}\right] .
\end{aligned}
$$

Theorem 5. [2] Let $G_{1}$ and $G_{2}$ be two graphs with $\left|V\left(G_{i}\right)\right|=n_{i}$ and $\left|E\left(G_{i}\right)\right|=m_{i}$, where $i=1,2$. Then

$$
\begin{aligned}
M_{1}\left(G_{1} \nabla_{Q} G_{2}\right)= & 2\left[M_{1}\left(G_{1}\right)+M_{1}\left(G_{2}\right)+2 M_{2}\left(G_{1}\right)+M_{3}\left(G_{1}\right)\right. \\
& \left.+n_{1} n_{2}\left(n_{1}+n_{2}+2\right)+n_{2}\left(4 m_{1}+1\right)+4 m_{2}\left(n_{1}+1\right)\right] .
\end{aligned}
$$

Theorem 6. [2] Let $G_{1}$ and $G_{2}$ be two graphs with $\left|V\left(G_{i}\right)\right|=n_{i}$ and $\left|E\left(G_{i}\right)\right|=m_{i}$, where $i=1,2$. Then

$$
\begin{aligned}
M_{2}\left(G_{1} \nabla_{Q} G_{2}\right)= & M_{1}\left(G_{2}\right)+4 m_{2}\left(n_{1}+1\right)+n_{2}\left(n_{1}+1\right)^{2}+2\left[2 n_{2} M_{1}\left(G_{1}\right)+\left(n_{1}+1\right) M_{1}\left(G_{2}\right)\right. \\
& +M_{2}\left(G_{2}\right)+\frac{1}{2}\left(M_{3}\left(G_{1}\right)+M_{4}\left(G_{1}\right)\right)+\left(n_{1}+1\right)\left\{m_{2}\left(n_{1}+1\right)\right. \\
& \left.+n_{2}\left(2 m_{1}+n_{1} n_{2}\right)\right\}+2 m_{2}\left(2 m_{1}+n_{1} n_{2}\right)+\sum_{u, w \in V\left(G_{1}\right)} \gamma_{u w} d_{G_{1}}(u) d_{G_{1}}(w) \\
& \left.+\sum_{u \in V\left(G_{1}\right)} d_{G_{1}}^{2}(u) \sum_{\substack{v \in V\left(G_{1}\right), u v \in E\left(G_{1}\right)}} d_{G_{1}}(v)\right],
\end{aligned}
$$

where $\gamma_{u w}$ is the number of common neighbors of $u, w \in V\left(G_{1}\right)$ and $M_{4}$ is the generalized first Zagreb index for $\alpha=4$. . 
Theorem 7. [2] Let $G_{1}$ and $G_{2}$ be two graphs with $\left|V\left(G_{i}\right)\right|=n_{i}$ and $\left|E\left(G_{i}\right)\right|=m_{i}$, where $i=1,2$. Then

$$
\begin{aligned}
M_{1}\left(G_{1} \nabla_{T} G_{2}\right)= & 2\left[4 M_{1}\left(G_{1}\right)+M_{1}\left(G_{2}\right)+2 M_{2}\left(G_{1}\right)+M_{3}\left(G_{1}\right)\right. \\
& \left.+n_{1} n_{2}\left(n_{1}+n_{2}+2\right)+n_{2}\left(8 m_{1}+1\right)+4 m_{2}\left(n_{1}+1\right)\right] .
\end{aligned}
$$

Theorem 8. [2] Let $G_{1}$ and $G_{2}$ be two graphs with $\left|V\left(G_{i}\right)\right|=n_{i}$ and $\left|E\left(G_{i}\right)\right|=m_{i}$, where $i=1,2$. Then

$$
\begin{aligned}
M_{2}\left(G_{1} \nabla_{T} G_{2}\right)= & M_{1}\left(G_{2}\right)+4 m_{2}\left(n_{1}+1\right)+n_{2}\left(n_{1}+1\right)^{2}+2\left[4 n_{2} M_{1}\left(G_{1}\right)+\left(n_{1}+1\right) M_{1}\left(G_{2}\right)\right. \\
& +6 M_{2}\left(G_{1}\right)+M_{2}\left(G_{2}\right)+\frac{1}{2}\left(3 M_{3}\left(G_{1}\right)+M_{4}\left(G_{1}\right)\right)+\left(n_{1}+1\right)\left\{m_{2}\left(n_{1}+1\right)\right. \\
& \left.+n_{2}\left(2 m_{1}+n_{1} n_{2}\right)\right\}+2 m_{2}\left(2 m_{1}+n_{1} n_{2}\right)+n_{2}^{2} m_{1} \\
& \left.+\sum_{u, w \in V\left(G_{1}\right)} \gamma_{u w} d_{G_{1}}(u) d_{G_{1}}(w)+\sum_{u \in V\left(G_{1}\right)} d_{G_{1}}^{2}(u) \sum_{\substack{v \in V\left(G_{1}\right), u v \in E\left(G_{1}\right)}} d_{G_{1}}(v)\right],
\end{aligned}
$$

where $\gamma_{u w}$ is the number of common neighbors of $u, w \in V\left(G_{1}\right)$ and $M_{4}$ is the generalized first Zagreb index for $\alpha=4$. .

Now we propose the following theorems.

\section{Forgotten topological index}

Theorem 9. Let $\left|V\left(G_{i}\right)\right|=n_{i}$ and $\left|E\left(G_{i}\right)\right|=m_{i}$ be the number of vertices and edges in $G_{i} ; i=1,2$. Then,

$$
\begin{aligned}
M_{3}\left(G_{1} \nabla_{S} G_{2}\right)= & 2\left[3\left\{n_{2} M_{1}\left(G_{1}\right)+\left(n_{1}+1\right) M_{1}\left(G_{2}\right)\right\}+M_{3}\left(G_{1}\right)+M_{3}\left(G_{2}\right)\right. \\
& \left.+\left(n_{1}+1\right)^{2}\left\{n_{2}\left(n_{1}+1\right)+6 m_{2}\right\}+n_{2}^{2}\left(n_{1} n_{2}+6 m_{1}\right)+8 m_{1}\right] .
\end{aligned}
$$

Proof.

$$
\begin{aligned}
M_{3}\left(G_{1} \nabla_{S} G_{2}\right) & =2\left[\sum_{u \in V\left(G_{1} \nabla_{S} G_{2}\right)} d^{3}(u)\right] \\
& =2\left[\sum_{u \in V\left(G_{1}\right)} d^{3}(u)+\sum_{u \in V\left(G_{2}\right)} d^{3}(u)+\sum_{u \in V\left(S\left(G_{1}\right)\right) \backslash V\left(G_{1}\right)} d^{3}(u)\right]
\end{aligned}
$$

Case I:

$$
\begin{aligned}
\sum_{u \in V\left(G_{1}\right)} d^{3}(u) & =\sum_{u \in V\left(G_{1}\right)}\left[d_{G_{1}}(u)+n_{2}\right]^{3} \\
& =\sum_{u \in V\left(G_{1}\right)} d_{G_{1}}^{3}(u)+\sum_{u \in V\left(G_{1}\right)} n_{2}^{3}+3 n_{2} \sum_{u \in V\left(G_{1}\right)} d_{G_{1}}^{2}(u)+3 n_{2}^{2} \sum_{u \in V\left(G_{1}\right)} d_{G_{1}}(u) \\
& =M_{3}\left(G_{1}\right)+n_{1} n_{2}^{3}+3 n_{2} M_{1}\left(G_{1}\right)+6 n_{2}^{2} m_{1} .
\end{aligned}
$$




\section{Case II:}

$$
\begin{aligned}
\sum_{u \in V\left(G_{2}\right)} d^{3}(u)= & \sum_{u \in V\left(G_{2}\right)}\left[d_{G_{2}}(u)+n_{1}+1\right]^{3} \\
= & \sum_{u \in V\left(G_{2}\right)} d_{G_{2}}^{3}(u)+\sum_{u \in V\left(G_{2}\right)}\left(n_{1}+1\right)^{3} \\
& +3\left(n_{1}+1\right) \sum_{u \in V\left(G_{2}\right)} d_{G_{2}}^{2}(u)+3\left(n_{1}+1\right)^{2} \sum_{u \in V\left(G_{2}\right)} d_{G_{2}}(u) \\
= & M_{3}\left(G_{2}\right)+n_{2}\left(n_{1}+1\right)^{3}+3\left(n_{1}+1\right) M_{1}\left(G_{2}\right)+6 m_{2}\left(n_{1}+1\right)^{2} .
\end{aligned}
$$

\section{Case III:}

$$
\sum_{u \in V\left(S\left(G_{1}\right)\right) \backslash V\left(G_{1}\right)} d^{3}(u)=\sum_{u \in V\left(S\left(G_{1}\right)\right) \backslash V\left(G_{1}\right)}(2)^{3}=8 m_{1} .
$$

Now combining all these three cases we get the desired result.

Theorem 10. Let $\left|V\left(G_{i}\right)\right|=n_{i}$ and $\left|E\left(G_{i}\right)\right|=m_{i}$ be the number of vertices and edges in $G_{i} ; i=1,2$. Then,

$$
\begin{aligned}
M_{3}\left(G_{1} \nabla_{R} G_{2}\right)= & 2\left[3\left\{4 n_{2} M_{1}\left(G_{1}\right)+\left(n_{1}+1\right) M_{1}\left(G_{2}\right)\right\}+8 M_{3}\left(G_{1}\right)+M_{3}\left(G_{2}\right)\right. \\
& \left.+\left(n_{1}+1\right)^{2}\left\{n_{2}\left(n_{1}+1\right)+6 m_{2}\right\}+n_{2}^{2}\left(n_{1} n_{2}+12 m_{1}\right)+8 m_{1}\right],
\end{aligned}
$$

\section{Proof. Case I:}

$$
\begin{aligned}
\sum_{u \in V\left(G_{1}\right)} d^{3}(u) & =\sum_{u \in V\left(G_{1}\right)}\left[2 d_{G_{1}}(u)+n_{2}\right]^{3} \\
& =8 M_{3}\left(G_{1}\right)+n_{1} n_{2}^{3}+12 n_{2} M_{1}\left(G_{1}\right)+12 n_{2}^{2} m_{1} .
\end{aligned}
$$

\section{Case II:}

$$
\begin{aligned}
\sum_{u \in V\left(G_{2}\right)} d^{3}(u) & =\sum_{u \in V\left(G_{2}\right)}\left[d_{G_{2}}(u)+n_{1}+1\right]^{3} \\
& =M_{3}\left(G_{2}\right)+n_{2}\left(n_{1}+1\right)^{3}+3\left(n_{1}+1\right) M_{1}\left(G_{2}\right)+6 m_{2}\left(n_{1}+1\right)^{2} .
\end{aligned}
$$

\section{Case III:}

$$
\sum_{u \in V\left(R\left(G_{1}\right)\right) \backslash V\left(G_{1}\right)} d^{3}(u)=\sum_{u \in V\left(R\left(G_{1}\right)\right) \backslash V\left(G_{1}\right)}(2)^{3}=8 m_{1} .
$$

Combinig Case I, II and III we get the result. 
Theorem 11. Let $\left|V\left(G_{i}\right)\right|=n_{i}$ and $\left|E\left(G_{i}\right)\right|=m_{i}$ be the number of vertices and edges in $G_{i} ; i=1,2$. Then,

$$
\begin{aligned}
M_{3}\left(G_{1} \nabla_{Q} G_{2}\right)= & 2\left[3\left\{n_{2} M_{1}\left(G_{1}\right)+\left(n_{1}+1\right) M_{1}\left(G_{2}\right)\right\}+M_{3}\left(G_{1}\right)+M_{3}\left(G_{2}\right)\right. \\
& +M_{4}\left(G_{1}\right)+\left(n_{1}+1\right)^{2}\left\{n_{2}\left(n_{1}+1\right)+6 m_{2}\right\}+n_{2}^{2}\left(n_{1} n_{2}+6 m_{1}\right) \\
& \left.+3 \sum_{w w^{\prime} \in E\left(G_{1}\right)} d_{G_{1}}(w) d_{G_{1}}\left(w^{\prime}\right)\left\{d_{G_{1}}(w)+d_{G_{1}}\left(w^{\prime}\right)\right\}\right],
\end{aligned}
$$

where $M_{4}$ is the generalized first Zagreb index for $\alpha=4$.

\section{Proof.}

$$
\begin{aligned}
M_{3}\left(G_{1} \nabla_{Q} G_{2}\right)= & 2 \sum_{u \in V\left(G_{1} \nabla_{Q} G_{2}\right)} d_{\left(G_{1} \nabla_{Q} G_{2}\right)}^{3}(u) \\
= & 2\left[\sum_{u \in V\left(G_{1}\right)}+\sum_{u \in V\left(G_{2}\right)}+\sum_{u \in V\left(Q\left(G_{1}\right)\right) \backslash V\left(G_{1}\right)}\right] d_{\left(G_{1} \nabla_{Q} G_{2}\right)}^{3}(u) \\
= & 2\left[\left\{M_{3}\left(G_{1}\right)+n_{1} n_{2}^{3}+3 n_{2} M_{1}\left(G_{1}\right)+6 n_{2}^{2} m_{1}\right\}+\left\{M_{3}\left(G_{2}\right)+n_{2}\left(n_{1}+1\right)^{3}\right.\right. \\
& \left.+3\left(n_{1}+1\right) M_{1}\left(G_{2}\right)+6 m_{2}\left(n_{1}+1\right)^{2}\right\}+\left\{M_{4}\left(G_{1}\right)\right. \\
& \left.\left.+3 \sum_{w w^{\prime} \in E\left(G_{1}\right)} d_{G_{1}}(w) d_{G_{1}}\left(w^{\prime}\right)\left(d_{G_{1}}(w)+d_{G_{1}}\left(w^{\prime}\right)\right)\right\}\right]
\end{aligned}
$$

Hence the theorem.

Theorem 12. Let $\left|V\left(G_{i}\right)\right|=n_{i}$ and $\left|E\left(G_{i}\right)\right|=m_{i}$ be the number of vertices and edges in $G_{i} ; i=1,2$. Then,

$$
\begin{aligned}
M_{3}\left(G_{1} \nabla_{T} G_{2}\right)= & 2\left[3\left\{4 n_{2} M_{1}\left(G_{1}\right)+\left(n_{1}+1\right) M_{1}\left(G_{2}\right)\right\}+8 M_{3}\left(G_{1}\right)+M_{3}\left(G_{2}\right)+M_{4}\left(G_{1}\right)\right. \\
& +\left(n_{1}+1\right)^{2}\left\{n_{2}\left(n_{1}+1\right)+6 m_{2}\right\}+n_{2}^{2}\left(n_{1} n_{2}+12 m_{1}\right) \\
& \left.+3 \sum_{w w^{\prime} \in E\left(G_{1}\right)} d_{G_{1}}(w) d_{G_{1}}\left(w^{\prime}\right)\left(d_{G_{1}}(w)+d_{G_{1}}\left(w^{\prime}\right)\right)\right] .
\end{aligned}
$$

where $M_{4}$ is the generalized first Zagreb index for $\alpha=4$. 


\section{Proof.}

$$
\begin{aligned}
M_{3}\left(G_{1} \nabla_{T} G_{2}\right)= & 2 \sum_{u \in V\left(G_{1} \nabla_{T} G_{2}\right)} d_{\left(G_{1} \nabla_{T} G_{2}\right)}^{3}(u) \\
= & 2\left[\sum_{u \in V\left(G_{1}\right)}+\sum_{u \in V\left(G_{2}\right)}+\sum_{u \in V\left(T\left(G_{1}\right)\right) \backslash V\left(G_{1}\right)}\right] d_{\left(G_{1} \nabla_{T} G_{2}\right)}^{3}(u) \\
= & 2\left[\sum_{u \in V\left(G_{1}\right)}\left(2 d_{G_{1}}(u)+n_{2}\right)^{3}+\sum_{u \in V\left(G_{2}\right)}\left(d_{G_{1}}(u)+n_{1}+1\right)^{3}\right. \\
& \left.+\sum_{u \in V\left(T\left(G_{1}\right)\right) \backslash V\left(G_{1}\right)}\left(d_{G_{1}}(w)+d_{G_{1}}\left(w^{\prime}\right)\right)^{3}\right] \\
& \quad u \text { is assume to be inserted in } w w^{\prime} \in E\left(G_{1}\right) \\
= & 2\left[\left\{8 M_{3}\left(G_{1}\right)+n_{1} n_{2}^{3}+12 n_{2}^{2} m_{1}+12 n_{2} M_{1}\left(G_{1}\right)\right\}+\left\{M_{3}\left(G_{2}\right)\right.\right. \\
& \left.+n_{2}\left(n_{1}+1\right)^{3}+3\left(n_{1}+1\right) M_{1}\left(G_{2}\right)+6 m_{2}\left(n_{1}+1\right)^{2}\right\}+\left\{M_{4}\left(G_{1}\right)\right. \\
& \left.\left.+3 \sum_{w w^{\prime} E\left(G_{1}\right)} d_{G_{1}}(w) d_{G_{1}}\left(w^{\prime}\right)\left(d_{G_{1}}(w)+d_{G_{1}}\left(w^{\prime}\right)\right)\right\}\right]
\end{aligned}
$$

Hence the theorem.

\section{Reduced second Zagreb index}

Theorem 13. Let $\left|V\left(G_{i}\right)\right|=n_{i}$ and $\left|E\left(G_{i}\right)\right|=m_{i}$ be the number of vertices and edges in $G_{i} ; i=1,2$. Then,

$$
\begin{aligned}
R M_{2}\left(G_{1} \nabla_{S} G_{2}\right)= & \left(1+2 n_{1}\right) M_{1}\left(G_{2}\right)+2 M_{2}\left(G_{2}\right)+n_{1}^{2}\left(1+2 m_{2}+2 n_{2}^{2}-2 n_{2}\right) \\
& +n_{1}\left(2-n_{2}+4 m_{1}+4 n_{2} m_{1}+4 n_{2} m_{2}-8 m_{2}\right) \\
& +m_{1}\left(12 n_{2}+8 m_{2}-4\right)+4 m_{2} n_{2}+1 .
\end{aligned}
$$

Theorem 14. Let $\left|V\left(G_{i}\right)\right|=n_{i}$ and $\left|E\left(G_{i}\right)\right|=m_{i}$ be the number of vertices and edges in $G_{i} ; i=1,2$. Then,

$$
\begin{aligned}
R M_{2}\left(G_{1} \nabla_{R} G_{2}\right)= & 4 n_{2} M_{1}\left(G_{1}\right)+n_{1} M_{1}\left(G_{2}\right)+4 M_{2}\left(G_{1}\right)+M_{2}\left(G_{2}\right) \\
& +\left(n_{1}+1\right)^{2}\left(2 m_{2}+n_{2}\right)+\left(n_{1}+1\right)\left(8 m_{1} n_{2}+2 n_{1} n_{2}^{3}-4 m_{2}\right) \\
& +8 m_{1}\left(2 m_{2}-n_{2}\right)+2 n_{1} n_{2}\left(2 m_{2}-n_{1}-n_{2}-1\right)+m_{1} n_{2}^{2}+2 m_{1} \\
& +2 m_{2}-n_{2} .
\end{aligned}
$$

Theorem 15. Let $\left|V\left(G_{i}\right)\right|=n_{i}$ and $\left|E\left(G_{i}\right)\right|=m_{i}$ be the number of vertices and 
edges in $G_{i} ; i=1,2$. Then,

$$
\begin{aligned}
R M_{2}\left(G_{1} \nabla_{Q} G_{2}\right)= & \left(4 n_{2}+2\right) M_{1}\left(G_{1}\right)+\left(2 n_{1}+1\right) M_{1}\left(G_{2}\right)-4 M_{2}\left(G_{1}\right)+2 M_{2}\left(G_{2}\right) \\
& -M_{3}\left(G_{1}\right)+M_{4}\left(G_{1}\right)+\left(2 m_{2}+n_{2}\right)\left(n_{1}+1\right)^{2}+4 m_{1}\left(m_{2}-2 n_{2}+1\right) \\
& +\left(n_{1}+1\right)\left(4 m_{1} n_{2}+2 n_{1} n_{2}^{2}-4 m_{2}\right)-2 n_{1} n_{2}\left(n_{1}+n_{2}\right) \\
& +n_{2}\left(2 m_{2} n_{1}-2 n_{1}-1\right)+2 m_{2}+2\left[\sum_{u, w \in V\left(G_{1}\right)} \gamma_{u w} d_{G_{1}}(u) d_{G_{1}}(w)\right. \\
& \left.+\sum_{u \in V\left(G_{1}\right)} d_{G_{1}}^{2}(u) \sum_{\substack{u \in V\left(G_{1}\right), u v \in E\left(G_{1}\right)}} d_{G_{1}}(v)\right]+2 \sum_{u \in V\left(G_{1}\right)}\left(\begin{array}{c}
d_{G_{1}}(v) \\
2
\end{array}\right),
\end{aligned}
$$

where $\gamma_{u w}$ is the number of common neighbors of $u, w \in V\left(G_{1}\right)$ and $M_{4}$ is the generalized first Zagreb index for $\alpha=4$.

Theorem 16. Let $\left|V\left(G_{i}\right)\right|=n_{i}$ and $\left|E\left(G_{i}\right)\right|=m_{i}$ be the number of vertices and edges in $G_{i} ; i=1,2$. Then,

$$
\begin{aligned}
R M_{2}\left(G_{1} \nabla_{T} G_{2}\right)= & 8\left(n_{2}-1\right) M_{1}\left(G_{1}\right)+\left(2 n_{1}+1\right) M_{1}\left(G_{2}\right)+8 M_{2}\left(G_{1}\right)+2 M_{2}\left(G_{2}\right) \\
& +M_{3}\left(G_{1}\right)+M_{4}\left(G_{1}\right)+\left(n_{1}+1\right)^{2}\left(n_{2}+2 m_{2}\right) \\
& +\left(n_{1}+1\right)\left(4 m_{2}+4 m_{1} n_{2}+2 n_{1} n_{2}^{2}\right)-2 n_{1} n_{2}\left(n_{1}+n_{2}\right) \\
& +\left(4 m_{2} n_{1}-2 n_{1}+m_{1} n_{2}-16 n_{1}-1\right) n_{2}+m_{2}\left(8 m_{1}-8 n_{1}-6\right) \\
& +6 m_{1}+2\left[\sum_{u, w \in V\left(G_{1}\right)} \gamma_{u w} d_{G_{1}}(u) d_{G_{1}}(w)\right. \\
& \left.+\sum_{u \in V\left(G_{1}\right)} d_{G_{1}}^{2}(u) \sum_{\substack{u \in V\left(G_{1}\right), u v \in E\left(G_{1}\right)}} d_{G_{1}}(v)\right]+2 \sum_{u \in V\left(G_{1}\right)}\left(\begin{array}{c}
d_{G_{1}}(v) \\
2
\end{array}\right),
\end{aligned}
$$

where $\gamma_{u w}$ is the number of common neighbors of $u, w \in V\left(G_{1}\right)$ and $M_{4}$ is the generalized first Zagreb index for $\alpha=4$.

Theorem 13 to theorem 16 can be proved using the relation $R M_{2}(G)=M_{2}(G)-$ $M_{1}(G)+|E(G)|$ and the Lemmas 2-6

\section{Conclusion}

The authors of this paper proposed four new operations based on Indu-Bala product and computed the first and second Zagreb indices of these operations [2]. In this communication, we establish explicit formulas of the forgotten index and reduced second Zagreb index for the four new operations of graphs.

\section{Acknowledgement}

The authors are thankful to the anonymous reviewers for carefully reading our manuscript and for their valuable comments. 


\section{References}

[1] S. Akhter, M. Imran, Computing the forgotten topological index of four operations of graphs, AKCE International Journal of Graphs and Combinatorics, vol. 14 , no. $1,2017,70-79$.

[2] A. Bharali, A, Mahanta, J. Buragohain, Four new operations of graphs and their Zagreb indices, submitted manuscript, 2018.

[3] D. M. Cvetković, M. Doob, H. Sachs, Spectra of Graphs: Theory and Application, Academic Press, 1980.

[4] N. De, Sk. Nayeem, A. Md., A. Pal, F-index of some graph operations, Discrete Mathematics Algorithms and Applictaions, vol. 8, no. 2, 2016, 1650025.

[5] H. Deng, D. Saralab, S. K. Ayyaswamy, S. Balachandran, The Zagreb indices of four operations on graphs, Appl. Math. and Comput.,vol. 275, 2016, 422-431.

[6] M. Eliasi, D. Taeri, Four new sums of graphs and their Wiener indices, Discrete Applied Mathematics, vol. 157, 2009, 794-803.

[7] C. M. Da Fonseca, D. Stevanović, Further Properties of the Second Zagreb Index, MATCH Commun. Math. Comput. Chem., vol. 72, 2014, 655-668.

[8] B. Furtula, I. Gutman, A forgotten topological index, J. Math. Chem., vol. 53, $2015,1187-1190$.

[9] B. Furtula, I. Gutman, E. Süleyman, On difference of Zagreb indices, Discrete Applied mathematices,vol. 178, 2014, 83-88.

[10] I. Gutman, K. C. Das, The First Zagreb Index 30 Years After, MATCH Commun. Math. Comput. Chem., vol. 50, 2004, 83-92.

[11] I. Gutman, N. Trinajstić, Graph theory and molecular orbitals. Total $\pi$-electron energy of alternant hydrocarbons, Chem. Phys. Lett.,vol. 17, no. 4, 1972, 535538.

[12] I. Gutman, E. Milovanović, I. Milovanović, Beyond the Zagreb index, AKCE nternational Journal of Graphs and Combinatorics, Available online 19 June 2018. https://doi.org/10.1016/j.akcej.2018.05.002.

[13] G. Indulal, R. Balakrishnan, Distance spectrum of Indu-Bala product of graphs, AKCE International Journal of Graphs and Combinatorics, vol. 13, no. 3, 2016, 230-234.

[14] M. H. Khalifeh, H. Yousefi-Azari, A. R. Ashrafi, The first and second Zagreb indices of some graph operations, Discr. Appl. Math., vol. 157, 2009, 804-811. 
[15] X. Li, H. Zhao, Trees with the first three smallest and largest generalized topological index, MATCH Commun. Math. Comput. Chem., vol. 50, 2004, 57-62.

[16] X. Li, J. Zheng, A unified approach to the extremal trees for different indices, MATCH Commun. Math. Comput. Chem., vol. 54, 2005, 195-208.

[17] P. Sarkar, N. De, N. I. Congul, A. Pal, The (a,b)-Zagreb index of some derived networks, Journal of Taibah University for Science, vol. 13, no. 1, 2019, 79-86.

[18] D. Sarala, H. Deng, S. K. Ayyaswami, S. Balachandran, The Zagreb indices of graphs based on four new operations related to the lexicographic product, Appl. Math. Comput.,vol. 309, 2017, 156-169.

[19] P. Sarkar, N. De, A. Pal, The Zagreb indices of graphs based on new operations related to the join of graphs, J. Int. Math. Virtual Inst., vol. 7, 2017, 181-209.

[20] G. Su, Z. Tu, K. C. Das, Graphs with fix number of pendent vertices and minimal zeroth order general Randić index, Appl. Math. Comput., vol. 270, 2015, 705710 .

[21] D. B. West, Introduction to graph theory, Prentice Hall India, 2002.

[22] B. Zhou, I. Gutman, Further properties of Zagreb indices, MATCH Commun. Math. Comput. Chem.,vol. 54, 2005, 233-239.

\title{
A. Bharali \\ Dibrugarh University \\ Department of Mathematics \\ Assam 786004, India \\ e-mail: a.bharali@dibru.ac.in
}

\author{
Abhigyan Mahanta \\ Dibrugarh University \\ Department of Mathematics \\ Assam 786004, India \\ e-mail: am02dib@gmail.com
}

\section{Jibonjyoti Buragohain}

Dibrugarh University

Department of Mathematics

Assam 786004, India

e-mail: j.bgohain75@yahoo.com 